\title{
BMJ Open Survey of workflow and cost implications of decommissioning regarding the Falsified Medicines Directive in Hungarian hospital pharmacies
}

\author{
Péter Vajda (D) , ${ }^{1,2}$ Katalin Richter, ${ }^{3}$ Zsolt Bodrogi (D) , ${ }^{1}$ Robert G Vida (D) , \\ Lajos Botz (D) ,' Sándor Kovács (D) , ${ }^{2}$ Antal Zemplényi (1) , ${ }^{2}$ Richárd Bella (1) , , \\ Andras Fittler (i) ${ }^{1}$
}

To cite: Vajda P, Richter K, Bodrogi Z, et al. Survey of workflow and cost implications of decommissioning regarding the Falsified Medicines Directive in Hungarian hospital pharmacies. BMJ Open 2021;11:e047193. doi:10.1136/ bmjopen-2020-047193

- Prepublication history and additional supplemental material for this paper are available online. To view these files, please visit the journal online (http://dx.doi.org/10.1136/ bmjopen-2020-047193).

Received 24 November 2020 Accepted 25 October 2021

D) Check for updates

(c) Author(s) (or their employer(s)) 2022. Re-use permitted under CC BY-NC. No commercial re-use. See rights and permissions. Published by BMJ.

${ }^{1}$ Department of Pharmaceutics and Central Clinical Pharmacy, Pécsi Tudományegyetem, Pecs, Hungary

${ }^{2}$ Division of

Pharmacoeconomics, Pécsi Tudományegyetem, Pecs, Hungary

${ }^{3}$ Department of Pharmacy, Szent Borbála Kórház, Tatabanya, Hungary

Correspondence to Dr Andras Fittler;

fittler.andras@pte.hu

\section{ABSTRACT}

Objectives, setting and participants In July 2011, the EU adopted the Falsified Medicines Directive (FMD) primarily aiming to prevent the infiltration of falsified medicines into the legitimate supply chain. Our aim was to measure the cost elements of FMD implementation and operation using an internationally adaptable tool among Hungarian hospital pharmacies.

Design A 41-item questionnaire was developed to evaluate the implementation process and associated cost consequences leading up to February 2019, and the stabilisation period.

Results Our representative data are supported by the high response rate, as $44.8 \%$ of the Hungarian hospital pharmacies have completed the survey. Human resource requirements related to decommissioning activities were measured as working hours and were expressed in full time equivalent (FTE). We have found an increased workload with extra 0.25 pharmacist and 0.75 technician FTE/institution at the end of the stabilisation period. The entire infrastructural and IT implementation costs were determined as $€ 2173$, on average (SD: $€ 3366$ ) and the median was $€ 1506$ (range: $€ 0-€ 20723$ ). The total IT investment cost per institution was valued at $€ 1410$ (SD: $€ 335)$. We identified a positive correlation $(R=0.663)$ in consideration of the costs, the number of beds and the number of hospital locations with a multivariate linear regression model. At the time of our survey, $76.7 \%$ of the respondents experienced drug shortages, $58.1 \%$ reported suspected increase in drug costs regarding serialised medications, and $53.5 \%$ noticed an increase in packaging size.

Conclusions Notably, our research is the first complex study depicting FMD cost implications in the hospital pharmacy sector in Central Europe, indicating decommissioning significantly impacted workflow referencing human resources and IT.

\section{INTRODUCTION}

The globalisation of the pharmaceutical supply chain, the reduction of trade barriers

\section{STRENGTHS AND LIMITATIONS OF THIS STUDY}

$\Rightarrow$ Our advanced method can be ideally used in areas of quality management and monitoring purposes regarding procedures related to the Falsified Medicines Directive (FMD) regulation and decommissioning.

$\Rightarrow$ We provide the first real-world evidence regarding the implementation and stabilisation period of FMD in the hospital pharmacy sector in Central Europe.

$\Rightarrow$ Our method can be easily adapted in a variety of inpatient healthcare institutions.

$\Rightarrow$ Our method was developed based on clinical practice in Hungary and we did not include the scanning time in our study.

$\Rightarrow$ Since we introduced our survey immediately following the initiation phase, our colleagues did not have enough experience and may have overestimated related phenomenon (eg, drug shortages and price increases).

and the augmentation of parallel trade practices have led to an extremely complex global ecosystem consisting of many actors and participants. As the complexity of the supply chain grows, medicinal products undergo multiple transactions from the manufacturing until they reach the end-users. Consequently, the risk of falsification and substandard product infiltration into the legal drug supply chains is the increase. ${ }^{1-4}$ However, not all of the countries are exposed to the same risk. In high-income countries, the regulation of the pharmaceutical supply chain ensures higher protection against patients receiving unsafe products compared with low-income and middle-income countries. ${ }^{1-10}$

There are different estimations throughout literature regarding the global market share and prevalence of falsified medicine within the drug supply chain. The global sale of 
falsified medicine is estimated to range from $€ 150$ billion to $€ 200$ billion annually and is the leading segment of the global counterfeiting market. ${ }^{11}$ In consideration of past decades, it was not possible to quantify the exact number of falsified medicines entering the legal supply chain, according to the European Commission Staff working document published in 2008, based on extrapolation from national figures by 2020, approximately $0.01 \%$ of all medicinal products dispensed via the legal supply will be falsified. ${ }^{12}$ The estimated cost effect in the European Economic Area ranges from $€ 1$ to $€ 3$ billion due to direct loss of income to pharmaceutical companies (sales) and governments (taxes). Furthermore, indirect losses are projected due to reputational or patent damage and societal costs associated with falsified medicine incidents. ${ }^{13}$

Although limited, several documented cases resulting in death occurred due to falsified products in the legitimate European and American supply chain, bringing recent anticounterfeiting measures to life. ${ }^{3} 1415$ Examples include the following cases presented by Venhuis $e t$ $a l$, a falsified gentamicin sulfate product imported into the USA; in the early 2000s in Japan, in which over 800 cases of liver damage was caused due to diet pills; in 2008 falsified heparin entered the US closed drug supply chain and claimed victims; in 2009, in Singapore and Hong Kong, potency-enhancing drugs contaminated with glibenclamide led to hospitalisation in more than 200 elderly males resulting in ten fatalities; and in subsequent years sibutramine and other dietary drugs were found to cause adverse cardiovascular drug reactions. ${ }^{16}$

LIn July 2011, the European Union (EU) adopted the Falsified Medicines Directive (FMD, Directive 2011/62/ EU of the European parliament and the council) aiming to prevent the infiltration of falsified medicines into the legitimate supply chain with the introduction of harmonised safety and strengthened control measures across Europe. The FMD requires most of the prescription-only and several over-the-counter medications to include a unique two-dimensional (2D) barcode identifier, while the majority of the nonprescription medicines are not in scope of FMD. Furthermore, tamper-proof seals must be used on the packaging and the authenticity of serialised packages must be verified prior to dispensing to patients. The authenticity of the medicines is verified by scanning a data matrix code on the packaging of medicine linked to a central or national database. The implementation of this end-to end system requires commissioning procedures during production affecting approximately 6000 pharmaceutical manufacturers and annually, upwards to 10 billion packages of prescription only medicines dispensed. Meanwhile, authentication and decommissioning are completed at the point of dispensing to patients. 1718

As of 2011, the Medicrime convention is the only existing criminal law convention focused on a public health topic in the European Union, which also has been ratified by Hungary and passed into law by the Hungarian
Parliament. The aim of the convention is to ensure signatory member states act in full accordance to uniform principles regarding the investigation and detection of criminal offences concerning the falsification of health products and similar crimes, which pose a threat to public health. ${ }^{19}$

Similarly, in the USA, the Drug Quality and Security Act was enacted by Congress on 27 November, 2013. Title II of the act (Drug Supply Chain Security Act) outlines steps to build an electronic, interoperable track-and trace system to identify certain prescription drugs as they are distributed throughout the USA. It includes the implementation of practices to improve detection and removal of potentially dangerous and falsified medications from the drug supply chain and establishment of national licensure standards for wholesale distributors and thirdparty logistics providers. ${ }^{2021}$

The estimated costs and potential benefits of the development and operation of the FMD for the supply chain actors have been evaluated by the European Commission (EC) impact assessment document from 2015 and its previous version, which was published in 2008 supporting the proposal for Directive 2011/62/EU.

In the case of retailers, the annual cost was estimated to be $€ 270-€ 530$ for each community pharmacy and up to $€ 390-€ 750$ for a European hospital pharmacy. ${ }^{12}$ Considering the number of pharmacies in the EU (154000 community pharmacies and 5000 hospital pharmacies), the total cost regarding the pharmacy distribution sector can reach nearly $€ 43-€ 85$ million annually. Solely for implementation and operation, since this estimate does not include indirect costs associated with price increases of serialised drugs and handling drug shortages. ${ }^{12} 22$ Generally speaking, when considering the totality of drugs included in the FMD, it was estimated the packaging line for applying the unique identifier cost could range from $€ 0.016$ to $€ 0.033$ per pack. If one multiplies the estimated price increase with the number of dispensed medication (18 billion annually), the rough estimates suggest a $€ 0.3-€ 0.6$ billion cost increase in the EU. ${ }^{12}$

Previous studies performed within a hospital environment regarding the workflow of the FMD showed decommissioning is performed in the dispensary prior to supplying the drugs to the wards or to other hospitals. Other examples include the decommissioning once the drugs are dispensed to the wards or established at checkout when drugs arrived to the ward (see figure 1). The procedure used for medicine authentication is also influenced by the suppliers and the ratio of wholesaler/ company orders. ${ }^{23-25}$

Thus far, there are limited data available referencing how FMD regulations are implemented and serialisation has influenced the drug dispensing process or hospital pharmacy workflow, since published studies focus mainly on the authentication and decommissioning steps. Additionally, data are only available regarding the preimplementation period (current as of February 2019) and limited information is accessible 


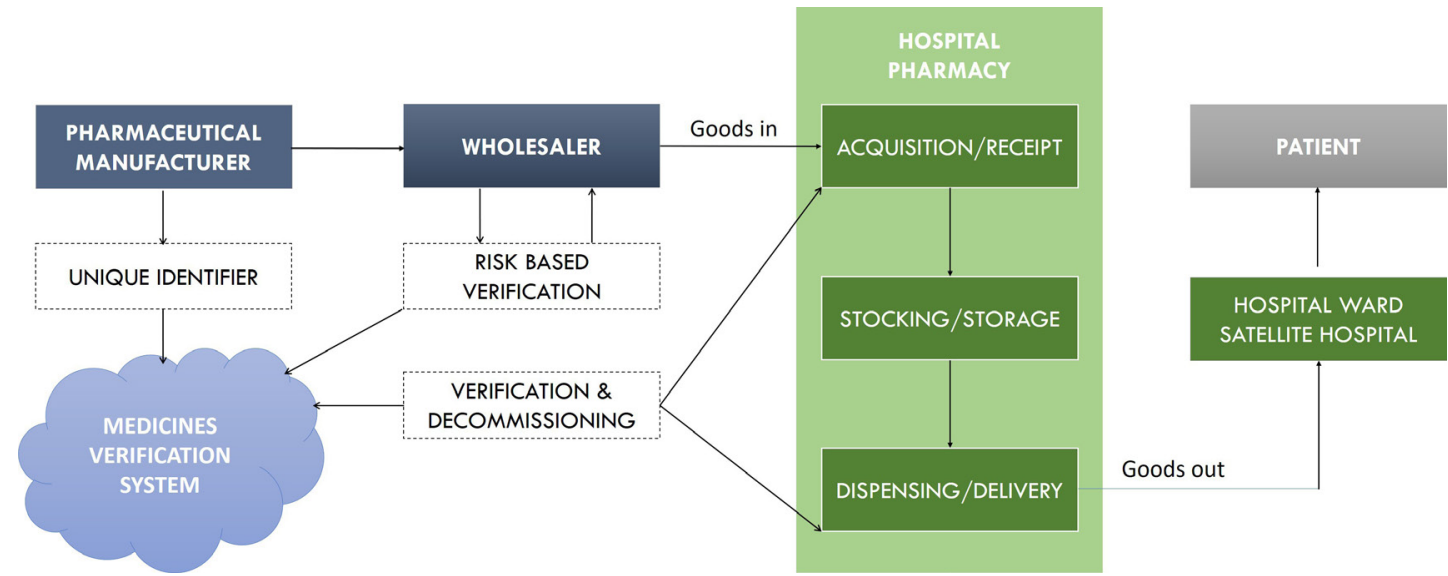

Figure 1 Process and workflow of decommissioning in hospital pharmacy setting based on the FMD. FMD, Falsified Medicines Directive.

regarding the stabilisation period beginning in February 2019. Naughton et al conducted their study prior to the launching of the FMD and focused on decommissioningrelated work processes and time. They provide useful information on the management and user aspects of the system. The article includes the presentation and dissemination of a validation protocol, and also identifies areas for improvement and potential problems, with the aim towards considering, and if necessary, improving these areas prior to launching the system. ${ }^{26}$ In comparison, our study focuses on the first 7 months of the postlaunch phase, addressing the costs of the infrastructure and information technology (IT) support necessary for the start-up, assuring smooth operation of the system, the assessment of the increased human resources required and the workflow itself.

As depicted from the summarised data above, during the time of codification regarding the FMD, data was limited regarding performing an effective, cost-benefit analysis. Currently, we are still lacking up-to-date information in reference to the actual costs associated with the directive, thus, the Authors designed the current study methodology to collect relevant data regarding the implication within a hospital pharmacy setting.

\section{AIMS}

Our aim was to evaluate the current practices, workload and financial implications of the implementation of the FMD regulation in a representative sample including Hungarian hospitals during the first 7 months of the stabilisation period. Additionally, we aimed to develop an internationally adaptable method regarding a standardised cost analysis of decommissioning in hospital setting.

\section{METHODS}

We searched for relevant peer-reviewed articles in four electronic databases (Google Scholar, PubMed, Research gate and Science Direct) and for grey literature in the
Google search engine with previously defined search terms: "falsified medicines directive" and "cost"; "FMD implementation" and "cost"; "FMD implementation" and "hospitals".

Initially, we began with unstructured personal and email consultation among practising clinical and hospital pharmacy specialists towards expanding our horizons and to effectively develop a detailed questionnaire referencing hospital aspects of the FMD and hospital pharmacy practice suitable for data collection. Preliminary consultations took place over six different occasions between June and August 2019, in which we involved three in-house (Pécs) and three out-of-house colleagues from a total of three different institutions, all employed in the position of chief pharmacist or a pharmacist. The final questionnaire was preceded by five preliminary trial versions, which were examined by the institutions participating in the development and design of the questionnaire. Next, we disseminated our questionnaire to the chief pharmacist of all Hungarian hospital pharmacies in September 2019, routed through the Hungarian Society of Hospital Pharmacists. As duly noted, we have thoroughly examined face validity and pilot tested our instrument. Based on the overview of literature and interviews with hospital pharmacy experts, a 41-item questionnaire was developed to evaluate the implementation process leading up to February 2019, and the ensuing stabilisation period which followed (see online supplemental 1). Questions regarding institutional data, human resource requirements, infrastructural and IT developments (non-human resource investments) and authentication procedures were disseminated to all $(\mathrm{n}=96)$ Hungarian hospital pharmacies via the Hungarian Society of Hospital Pharmacists in September 2019.

The questionnaire is divided into three main sections: institutional data and human resource requirements; infrastructural and IT developments; and authentication procedures. Respondents were requested to provide human resource and infrastructural and IT development data for two time frames: the implementation process 
until February 2019, and the following stabilisation period. In the first section, basic institutional characteristics were described, including the professionals' workload related to decommissioning. Employees work hours dedicated to FMD related duties are expressed in fulltime equivalent (FTE), calculated by the hours assigned to decommissioning divided by 40 hours representative of a full-time workweek. Additionally, the first part of the questionnaire assessed the number of active and chronic beds served, sites of reception of drug products from wholesalers, units performing verification and decommissioning, and information on contracted institutions. The second section focused on the infrastructure and IT developments related to FMD. Respondents provided data on computers/laptops, monitors, various barcode scanners and associated self-financed costs, advancing new premises and much needed additional storing capacities. The third section discussed the methodology and workflow regarding daily practice, the professional steps of verification and decommissioning, including storage. Additionally, the number of total medication packs and those with unique identifiers entering the pharmacy were evaluated. Lastly, several indirect effects of the FMD, such as cost increases, drug shortages and box size changes were assessed.

At the end of each of the first three sections, we offered an opportunity to the respondents to freely express their comments, share their experiences and any other information, which resulted in additional costs regarding the implementation and operation of the FMD within their unit. We asked every respondent to substantiate answers by specifying the exact item and cost.

Although, the FMD affects all participants within the drug supply chain, our study focuses on hospital care setting, and, consequently, we explicitly asked our respondents not to report information regarding the outpatient care (community pharmacy) unit of their institution when answering questions.

Furthermore, data culled from 43 respondent institutions were used to estimate the entire Hungarian hospital care setting based on the number of hospital beds from the Hungarian PULVITA Health Data Warehouse $^{27}$ using a multivariate linear regression model. In addition to the descriptive statistics, we sought to determine whether there is any correlation between the parameters examined and collected in the questionnaire (see table 1.). Therefore, based on the resource use and unit cost reported by the respondents of our survey, we developed a multivariate linear regression model to identify parameters, which bears a significant effect on the total cost of serialisation. In a stepwise linear regression modelling, we introduced multiple parameters into the model to analyse their effect. Descriptive statistics and statistical analyses were conducted using the SPSS software V.26.
Table 1 Descriptive information and characteristics regarding hospital pharmacies participating in the study

No of inpatient hospital beds

Acute care (total) 20751

Mean acute beds/institution $( \pm \mathrm{SD}$ )

$482.6( \pm 390.2)$

Chronic care (total)

10983

Mean chronic beds/institution $( \pm \mathrm{SD}$ )

$255.4( \pm 175.1)$

Institution size category according to hospital beds $\mathrm{n}(\%)$

Small (less than 500 beds)

19 (44.2)

Medium (500-1000 beds)

$11(25.6)$

Large (more than 1000 beds)

$13(30.2)$

Regional classification $\mathrm{n}(\%)$

Capital

7 (16.3)

Rural

36 (83.7)

No of hospital pharmacy units receiving medications and performing decommissioning $\mathrm{n}^{\star}(\%)$

One

38 (88.4)

Two or more

5 (11.6)

Decommissioning technique $\mathrm{n}(\%)$

One step

32 (74.4)

Separate steps

$11(25.6)$

Operation of a community (retail) pharmacy unit $n(\%)$

Yes

30 (69.8)

No

13 (30.2)

No of separate institutions and health facilities supplied $n(\%)$

None

1

$13(30.2)$

Or more

8 (18.6)

${ }^{\star}$ Excluding community pharmacy unit of the hospital pharmacy.

\section{Patient and public involvement}

Patients and/or the public were not involved in the design, conduct, reporting or dissemination plans regarding this research.

\section{RESULTS}

Introduction of respondents, workflow of serialisation in hospitals and additional human resource requirements

A representative sample of hospital pharmacies $(n=43)$ completed the questionnaire, resulting in a $44.8 \%$ response rate. Institutional characteristics are summarised in table 1. We consider our findings representative to the Hungarian hospitals, in accordance to national bed count data in which responding institutions correspond to approximately half of all active (42 194) and chronic (24 514) beds within the country.

The number of receipt/goods in locations and verification sites were evaluated, since we assumed multiple receipt locations influence verification workload. A majority $(88.4 \%)$ of hospitals included within our study received products at only one central site and these units 
Table 2 Human resource and investment (infrastructure and IT) costs required for initial implementation and maintaining of serialisation for hospital pharmacies

\begin{tabular}{|c|c|c|c|c|c|c|c|c|c|c|c|}
\hline \multirow[b]{2}{*}{ Institution size } & & & \multicolumn{3}{|c|}{$\begin{array}{l}\text { Small } \\
1-500 \text { beds }\end{array}$} & \multicolumn{3}{|c|}{$\begin{array}{l}\text { Medium } \\
501-1000 \text { beds }\end{array}$} & \multicolumn{3}{|c|}{ Large above 1000 beds } \\
\hline & & & $\mathbf{n}$ & Mean & \pm SD & $\mathbf{n}$ & Mean & \pm SD & $\mathbf{n}$ & Mean & \pm SD \\
\hline \multirow{2}{*}{$\begin{array}{l}\text { Workload } \\
\text { increase* (hours/ } \\
\text { day/pharmacy) }\end{array}$} & Pharmacist & Future & \multirow{2}{*}{19} & 0.74 & 1.78 & \multirow{2}{*}{11} & 1.30 & 1.23 & \multirow{2}{*}{13} & 1.58 & 1.73 \\
\hline & Technician & Initial & & 2.03 & 1.54 & & 1.54 & 0.56 & & 3.19 & 1.32 \\
\hline \multirow{3}{*}{$\begin{array}{l}\text { Non-human } \\
\text { investments } † \\
\text { (EUR/pharmacy) }\end{array}$} & IT & Future & 5 & 853 & 345 & 5 & 1280 & 362 & 3 & 803 & 609 \\
\hline & \multirow[t]{2}{*}{ Infrastructure } & Initial & 2 & 226 & 106 & 3 & 224 & 328 & 7 & 2810 & 4930 \\
\hline & & Future & 3 & 873 & 740 & 3 & 497 & 613 & 0 & - & - \\
\hline
\end{tabular}

*Initial change until implementation as of February 2019, and estimated future change during the stabilisation period until all prescription-only medicine packages are serialised.

†Descriptive data are presented for institutions providing data on self-financed investments necessary to meet FMD requirements. Currency conversion rate is $€ 1=3$ HUF332, as of September 2019, the time of survey.

FMD, Falsified Medicines Directive.

performed the task at one site, while several $(11.6 \%)$ at two or more sites. More than half of hospital pharmacies did not have contracts with other inpatient institutions, and the remainder $(48.8 \%)$ served one or more health facilities.

Human resource requirements related to decommissioning duties were measured regarding working hours and expressed in FTE instead of monetary value, as wage-levels are considerably diversified among various countries. In February 2019, the launch date of FMD, the average increase in pharmacist workload was 0.92 $( \pm 0.98)$ hours/day, and respondents estimated it will further increase by $1.13( \pm 1.65)$ hours during the stabilisation period. Additionally, FMD seemed to increase technician workload more significantly when compared with pharmacists. Since February 2019, a $2.25( \pm 1.42)$ hours workload increase was estimated for technicians, and in the long term, an additional $4.01( \pm 3.88)$ working hour. Consequently, the increased workload due to decommissioning sums up to approximately 0.25 pharmacist and 0.75 technician FTE/institution by the end of the stabilisation period. Evidently, HR requirement and planning varies depending on the institution profile and hospital pharmacy characteristics, consequently, data representing different institution sizes are illustrated in table 2.

Time allocated in training new employees regarding the FMD related workflow and duties was assessed. Training is performed mainly by a specialist pharmacist, and in most institutions it required a negligible amount of time, approximately 1 hour (mode: 1 ) to train fellow specialist pharmacy technician colleagues. However, the length of the process showed a relatively high variation (mean: 3.0 hours, SD: 5.6).

\section{IT and infrastructural developments}

The second section of the questionnaire evaluated the non-human infrastructure and IT investment costs associated with the implementation of the FMD. Similar to section one, initial (as of February 2019) and the following short-term (stabilisation period) investment costs were evaluated. Required investments were documented in units (eg, square metres and the number of devices) and the monetary value (Hungarian Forint, HUF). The latter is presented in EUR, since cost levels of IT and infrastructure investment costs are internationally comparable.

A majority of the hospitals required PCs/laptops $(60.8 \%)$ and monitors $(67.4 \%)$ during the initial phase (mode: 1 and max: 4 per institution regarding both devices), while only a few hospitals $(<20 \%)$ projected such an investment necessary during the stabilisation period. The supplier and supporter of healthcare services in Hungary, the National Healthcare Service Centre, provided institutions with a limited number of handheld scanners. Consequently, hospital pharmacies required additional handheld scanners financed from the institution's own budget to implement serialisation, as most $(\mathrm{n}=23, \quad 55.8 \%)$ hospital pharmacies self-purchased scanner devices (mode:2, range: 1-14 per institution). Additionally, several installed more expensive fixed wideangle code scanners $(\mathrm{n}=1)$ or high performance singleplane/multiplane scanners $(n=3)$. However, it must be noted, the later devices were procured by larger hospitals with more than 1000 beds. Only four medium and large sized (above 500 beds) hospital pharmacies expressed a future need for this relatively expensive device during the stabilisation period. Consequently, $44.2 \%$ of the studied hospital pharmacies were able to implement serialisation tasks without investing in scanning devices, the remainder by procuring relatively low investment scanners, and 
several higher priced devices. The mean total IT investment cost per institution until implementation was valued at $€ 1410$ (SD: $€ 335$ ), including computers and scanners, while an additional $€ 301$ (SD: $€ 577$ ) financial need was estimated regarding the stabilisation period. In Hungary, the National Healthcare Service Centre provided two scanners to all participating institutions. The variable regarding data originated from various practices, since several hospitals, who procured scanners in which these were among their first, in contrast to those institutions, which needed to procure additional scanners due to the number of beds, or increased capacity.

Infrastructural development was calculated based on the necessary area increase for serialisation related activities (verification-decommissioning, storage and quarantine), and the acquisition of furniture and refurbishing of the affected areas (eg, desks, shelves, air-conditioning). An increase of FMD related premises was necessary in eleven hospitals (25.6\%) up through February 2019 (mean: 20.2, range $4-60 \mathrm{~m}^{2}$ ) and only two institutions planned minor $\left(<10 \mathrm{~m}^{2}\right)$ investments in the future. In summary, infrastructural development costs are illustrated in table 2 in reference to the different institutional size categories.

Considering the short-term and long-term workload increase, additional IT and infrastructural investments associated with the FMD in our nationally representative sample, we propose following units of measurement to illustrate, estimate and compare implications of serialisation within a hospital setting:

- Pharmacist workload increase 0.28 hours/day/100 beds.

- Technician workload increase 0.86 hours/day/100 beds.

- IT investment costs $€ 238.9 / 100$ beds.

- Infrastructure investment costs $€ 80.7 / 100$ beds.

\section{Workflow and procedures of serialisation}

In the third section of our study, we focused on the workflow and procedures of serialisation. The majority (74.4\%) of the institutions performed one-step implementation of the FMD (verification and decommissioning concurrently). The remainder $(25.6 \%)$, first verified the medications at goods-received, stocked the products and then prior to dispensing them to the hospital wards, in the form of a second step, the unique code is next scanned once more to deactivate the drug from the system. We hypothesised, this extra step may increase the workload of the hospital pharmacy staff, and/or the investment costs discussed above. Although the outcome measures (workload and IT costs) are somewhat higher for hospitals performing the two-step process, the differences are not statistically significant ( $>0.1$ independent sample t-test). More than half of respondents reported to store serialised products separately, whereas 18 institutions $(41.9 \%)$ did not separate formerly deactivated products from those which required deactivation.
At the time of implementation of the Directive, not all medications featured the data matrix code, and the number of serialised packages gradually increased during the first months of the stabilisation period.

Several alert messages were communicated by the system, including those most common, an unknown code or expired date issues, current as of 2019. ${ }^{28}$

In the event of suspected falsified medicine cases (eg, relevant formerly mentioned codes or damaged packaging or antitampering devices), institutions are encouraged to take responsible action. Responders reported hospital pharmacists averagely spend $25-30 \mathrm{~min}$ per case in effectively filing the report.

Interestingly, there are several potential indirect effects regarding the implementation of FMD. Based on more than half a year's worth of experience in decommissioning, numerous $(41.9 \%)$ institutions reported to have experienced a price increase regarding serialised medications. A majority $(88.4 \%)$ of hospitals experienced drug supply issues with products under the FMD regulation, more specifically $33(76.7 \%)$ reported FMD has created a drug shortage in their institutions. Differences in product packaging size may likely be of potential concern as a consequence, $23(53.5 \%)$ hospital pharmacies required an increase in storage capacity.

A multivariate linear regression model was developed to identify parameters, which bear a significant effect on the total cost of decommissioning initiated within their organisation. The model's coefficient of multiple correlation $(\mathrm{R})$ is 0.663 , indicating a moderate to high positive correlation between independent and dependent variables.

Based on our survey, including 43 hospital pharmacies, the total cost of implementing changes according to legal the requirement regarding FMD, was $€ 93438$. These units allocated $€ 2173$ on average (SD: $€ 3366)$ and the median was $€ 1506$ (range: $€ 0-€ 20723$ ).

Based on multivariate linear regression modelling, we found the total cost regarding decommissioning responses aligned only to the number of beds and the number of multiple localisation of the healthcare institutions as explanatory variables, and the $\beta$-values are 8548 $(\mathrm{p}=0.0055)$ and $1431253(\mathrm{p}=0.0025)$, respectively. These explanatory variables are related to the size of the healthcare providers in which the pharmacy units are operating in. Based on the linear model, we have extrapolated our results and estimated the total cost of serialisation in all Hungarian hospitals including an in-house clinical pharmacy unit. Estimated total cost is $€ 266596$, while the average cost hovers at $€ 2748$ (SD: $€ 3255$, median $€ 1102$, range: $€ 167-€ 13250)$.

\section{DISCUSSION AND CONCLUSION}

Our work fills a gap in printed literature, as there were only preliminary estimates available regarding the cost implications of the FMD in the drug supply system. Therefore, hospitals pharmacies did not know the magnitude 
and extent of the investments required for preparing nor during the stabilisation period. Although it was widely communicated in which the introduction of the FMD will make up for the ravenous loss due to the black market, this legislation only affects and tightens the legal drug supply chain, which does not imply an automatic shutdown of illegal infiltrators. In order to assess the entire supply chain effect of the FMD, a chain-wide and detailed data collection is required with the implementation and maintenance costs, similar to our study. Our method is suitable for the collection of above-mentioned detailed data from the hospital pharmacy sector, and can be implemented at European levels.

Although, it will be useful to conduct a cost-benefit analysis regarding antifalsification measures, taking into account all the direct and indirect costs and benefits, unfortunately, there is a lack of essential information. Without data on the penetration rate of falsified products within the supply chain, the actual global and national market of falsified pharmaceuticals, prevalence of patients consuming falsified medicines, etc, the healtheconomic analysis of this global falsified medicine issue is extremely difficult, allocation of value to single patient cases, drugs or geographical area is not yet feasible.

Mandatory mass-serialisation methods augment the traceability of medicines; consequently ensure the drug supply chains are safer and less attractive for counterfeiters. Currently, more than 40 countries around the world are implementing regulatory initiatives to secure pharmaceutical supply chains. ${ }^{29}$ However, there are still geographical and virtual shortcomings, as antifalsification legislations apply to limited number of countries and the global illicit internet medicine market is largely beyond the scope of these initiatives. Presently, these methods are not operating at $100 \%$, and this is supported by an estimate, in which only $35 \%-50 \%$ falsified medicines could be identified using mass serialisation techniques. ${ }^{11}$

Hospital pharmacists are faced with several challenges and practical issues related to the implementation of FMD. In addition to personnel resource issues and the procurement of new IT solutions evaluated, the variety of products and reimbursement models were a potential source of confusion and stress. To cite an example, several colleagues in our study were confused whether different medication categories should be decommissioned or simply left as is (eg, biologicals, clinical trial samples). Practical issues included inventory management system integration, unit dose dispensing and split packs, managing returns and ward stock, or slow decommissioning due to the lack of data matrix aggregation. Serialisation bears several benefits in addition to increasing patient safety, however, these advantages, such as faster product recalls and response in pharmacovigilance is expected, yet are not evident.

A previously published study by Hug $e t$ al focused on the documentation of workflows within a hospital setting and the analysis of the time taken to decommission medication packs. The median time to process each single pack required 2.1s (0.6-6.5s), and the authors have concluded, compared with a community pharmacy, in a large university-based hospital a much greater degree of planning and technical support is needed regarding on time decommissioning. ${ }^{30}$ The European Alliance for Access to Safe Medicines indicated in the case of large hospitals, additional human resources (2-4 extra FTEs of pharmacy technicians) are required since the FMD and more precisely, due to false negative and positive alerts. Additional costs are dependent on the authentication process used and the response or scanning time per packs. ${ }^{25} 3132$ Naughton evaluated key technical parameters in a simulated environment regarding serialisation and decommissioning and concluded, the response time of the repository system is not a rate-limiting step. ${ }^{17}$

Our study possesses both benefits and limitations. The high response rate $(\mathrm{n}=43,44.8 \%)$ is a major advantage since it permits representative data evaluation reflective of Hungarian hospitals. As opposed to preimplementation studies, the timing of our research allows us to monitor procedures and associated costs within an environment in which the quantity of medication packs with 2D data matrix codes were increasingly and consistently high. The main limitations are also linked to the timing of the questionnaire due to its structure. Since our study focused on the first 7 months regarding the serialisation, there was a general lack of experience and the workflow of pharmacies was not finalised, hence, pharmacists struggled with the different codes and false alarms. The structure of the questionnaire allowed the participants to skip any questions deemed incomprehensible in consideration of their experience.

In order to decrease the financial burden of verification and decommissioning and increase the efficiency of professional operations, local and national standard operating procedures must be reconsidered and best practices should be disseminated. Ideally, national pharmaceutical bodies provide guidance for failed decommissioning instances, such as falsified, offline and expired codes.

Currently, enthusiasm regarding anti-falsification measures is limited within the pharmaceutical supply chain. Serialisation is an essential measure; however, it will not independently cease falsification of medicinal products. In order to attract support and a higher level of commitment from all stakeholders, including drug manufacturers, intermediaries, healthcare professionals and patients, novel protective methods are needed with a higher risk-reward dividend. Until such new technologies are fully developed, available measures must be applied simultaneously, including informing the public regarding the risk and peril of falsified medicine, more effective international legislation and stringent law enforcement.

Contributors PV, AF, ZB and RGV conducted the hospital pharmacy questionnaire and collected the data, AF, PV, KR and ZB designed the study, PV, RGV, SK and AF conducted the data analyses, PV, AF, ZB, RB, SK, KR, RGV and AZ contributed to the interpretation of the results. PV and AF wrote the manuscript and approved the final version of the manuscript, $L B$ supervised the project, $A F$ is responsible for the overall content as guarantor, all authors discussed the results and commented on the manuscript. 
Funding The project has been supported by the European Union,co-financedby the European Social Fund (EFOP-3.6.1-16- 2016-00004), by the University of Pécs in the frame of Pharmaceutical Talent Centre programme and by the ÚNKP-19-I NewNational Excellence Programme of the Ministry for Innovation and Technology.

Competing interests None declared.

Patient consent for publication Not applicable.

Provenance and peer review Not commissioned; externally peer reviewed.

Data availability statement Data are available on reasonable request. Extra data (statistical analysis) is available by emailing Dr. Peter Vajda (vajda.peter@gytk.pte. hu).

Supplemental material This content has been supplied by the author(s). It has not been vetted by BMJ Publishing Group Limited (BMJ) and may not have been peer-reviewed. Any opinions or recommendations discussed are solely those of the author(s) and are not endorsed by BMJ. BMJ disclaims all liability and responsibility arising from any reliance placed on the content. Where the content includes any translated material, BMJ does not warrant the accuracy and reliability of the translations (including but not limited to local regulations, clinical guidelines, terminology, drug names and drug dosages), and is not responsible for any error and/or omissions arising from translation and adaptation or otherwise.

Open access This is an open access article distributed in accordance with the Creative Commons Attribution Non Commercial (CC BY-NC 4.0) license, which permits others to distribute, remix, adapt, build upon this work non-commercially, and license their derivative works on different terms, provided the original work is properly cited, appropriate credit is given, any changes made indicated, and the use is non-commercial. See: http://creativecommons.org/licenses/by-nc/4.0/.

\section{ORCID iDs}

Péter Vajda http://orcid.org/0000-0001-8788-482X

Zsolt Bodrogi http://orcid.org/0000-0003-0373-4117

Robert G Vida http://orcid.org/0000-0003-1176-0251

Lajos Botz http://orcid.org/0000-0003-0407-1247

Sándor Kovács http://orcid.org/0000-0002-6911-0537

Antal Zemplényi http://orcid.org/0000-0002-0177-0264

Richárd Bella http://orcid.org/0000-0001-7926-4030

Andras Fittler http://orcid.org/0000-0002-8243-6179

\section{REFERENCES}

1 Przyswa E. Counterfeit medicines and criminal organisations. Institute of Research against Counterfeit Medicines, IRACM [Internet], 2021: 8-9. https://globalinitiative.net/wp-content/uploads/2017/12/ IRACM-Counterfeit-Medicines-and-Criminal-Organizations-Oct2013.pdf

2 Cuomo RE, Mackey TK. An exploration of counterfeit medicine surveillance strategies guided by geospatial analysis: lessons learned from counterfeit Avastin detection in the US drug supply chain. BMJ Open 2014;4:e006657

3 Mackey TK, Cuomo R, Guerra C, et al. After counterfeit Avastin $®-$ -what have we learned and what can be done? Nat Rev Clin Oncol 2015;12:302-8.

4 Mackey TK, Liang BA, York P, et al. Counterfeit drug penetration into global legitimate medicine supply chains: a global assessment. $A m \mathrm{~J}$ Trop Med Hyg 2015;92:59-67.

5 Woo J, Wolfgang S, Batista $\mathrm{H}$. The effect of globalization of drug manufacturing, production, and sourcing and challenges for American drug safety. Clin Pharmacol Ther 2008;83:494-7.

6 Buckley GJ, Gostin LO. Countering the problem of Falsified and substandard drugs. Washington (DC: National Academies Press, 2013.

7 Taylor D. RFID in the pharmaceutical industry: addressing counterfeits with technology. J Med Syst 2014;38:141.

8 Bailey W. Globalization of the Life Sciences Supply Chain. [Internet]. Available: https://www.contractpharma.com/issues/2011-01/view_ features/globalization-of-the-life-sciences-supply-chain/

9 Mackey TK, Liang BA, York P, et al. Counterfeit drug penetration into global legitimate medicine supply chains: a global assessment. Am J Trop Med Hyg 2015;92:59-67.

10 Newton PN, Green MD, Mildenhall DC, et al. Poor quality vital antimalarials in Africa - an urgent neglected public health priority. Malar $J$ 2011;10:352.
11 Strategy\& Part of the PwC network. Fighting counterfeit pharmaceuticals \& New defenses for an underestimated - and growing - menace. Available: https://www.strategyand.pwc.com/ gx/en/insights/2017/fighting-counterfeit-pharmaceuticals/fightingcounterfeit-pharmaceuticals.pdf

12 European Commission. COMMISSION STAFF WORKING DOCUMENT IMPACT ASSESSMENT Accompanying the document COMMISSION DELEGATED REGULATION (EU) supplementing Directive 2001/83/EC of the European Parliament and of the Council by laying down detailed rules for the safety features appearing on the packaging of medicinal products for human use. [Internet]. Available: https://ec.europa.eu/smartregulation/impact/ia_carried_out/docs/ia 2015/swd_2015_0189_en.pdf

13 Alliance for Safe Online Pharmacy EU. Falsified medicines costing the earth. [Internet]. Available: https://eaasm.eu/wp-content/uploads/ FalsifiedMedicinescostingtheearth-2.pdf

14 Pisani E. WHO Global Surveillance and Monitoring System for substandard and falsified medical products. [Internet]. Available: https://www.who.int/medicines/regulation/ssffc/publications/gsmsreport-sf/en/

15 Almuzaini T, Sammons H, Choonara I. Substandard and falsified medicines in the UK: a retrospective review of drug alerts (20012011). BMJ Open 2013;3:e002924.

16 Venhuis BJ, Mosimann R, Scammell L. Identification of health damage caused by Medicrime products in Europe: an exploratory study. Available: https://www.rivm.nl/bibliotheek/rapporten/ 040003001.pdf

17 Naughton BD. Medicine authentication technology: a quantitative study of incorrect quarantine, average response times and offline issues in a hospital setting. BMJ Open 2019;9:e026619.

18 Smith G, Smith JA, Brindley DA. The Falsified medicines directive: how to secure your supply chain. J Generic Med 2014;11:169-72.

19 Council of Europe. Council of Europe Convention on the counterfeiting of medical products and similar crimes involving threats to public health. [Internet]. Available: https://www.coe.int/en/ web/conventions/full-list/-/conventions/rms/090000168008482f

20 Brechtelsbauer ED, Pennell B, Durham M, et al. Review of the 2015 drug supply chain security act. Hosp Pharm 2016;51:493-500.

21 U.S. Food and Drug Administration. Available: https://www.fda.gov/

22 Van Baelen M, Dylst P, Pereira CL, et al. Fighting counterfeit medicines in Europe: the effect on access to medicines. Med Access Point Care 2017;1:maapoc.0000010.

23 Naughton B, Smith JA, Ohanjanyan A. EU FMD: hospital pharmacy challenges and opportunities. [Internet]. Available: https://hospital pharmacyeurope.com/news/editors-pick/eu-fmd-hospital-pharmacychallenges-and-opportunities/

24 Pinto de CN, Koshkouei MJ, Jeske M. The impact of the Falsified medicines directive in the dispensing operations of an Austrian Hospital pharmacy. J Hosp Med Manage 2017;3:1.

25 Burri S, Scheidegger R. The EU Falsified Medicines Directive - A Concept for Drug Decommissioning in Hospitals. Stud Health Technol Inform 2019;259:91-4.

26 Naughton B, Roberts L, Dopson S, et al. Effectiveness of medicines authentication technology to detect counterfeit, recalled and expired medicines: a two-stage quantitative secondary care study. BMJ Open 2016;6:e013837

27 PULVITA Health Data Warehouse [Internet]. Available: https://www. eadatlap.hu/PULVITAsysR2/SysLogin/index.php

28 European Medicines Verification Organisation. EMVO monitoring report - calendar week 20 - 2020. Available: https://emvo-medicines eu/new/wp-content/uploads/2020CW20_EMVO-Monitoring-Report_ Final.pdf

29 Adents. Global Serialization Landscape for Pharmaceutical Products: The Map. [Internet]. Available: https://adents.com/resource-globalserialization-landscape-pharmaceutical-products-1025.html

30 Hug MJ, Pinto de CN, Mack C. Impact of the implementation of the Falsified Medicines Directive on a healthcare institution [Internet]. Available: https://www.eahp.eu/sites/default/files/2spd-029.pdf

31 European Alliance for Access to Safe Medicines. The Falsified Medicines Directive - implementing practical solutions in the hospital arena A report of the EU Parliament meeting that brought together experts to support knowledge sharing and best practices around processes and authentication. [Internet]. Available: https://eaasm.eu/ wp-content/uploads/EAASMreport-TheFMD-Implementingpractica IsolutionsinthehospitalarenaMarch2019_.pdf

32 Süle A. A gyógyszerhamisításon túl - az egyedi dobozazonosító rendszer kórházi vetületei. IME - Interdiszciplináris Magyar Egészségügy 2018;17:51-5. 